\title{
РАЗРАБОТКА НОВОГО ВИДА ЗЕФИРА ЧЕРНОСМОРОДИНОВОГО С ИСПОЛЬЗОВАНИЕМ БАЗИЛИКА
}

N.V. Prisukhina, L.G. Ermosh, N.N. Tipsina, P.V. Osetrova

\section{THE DEVELOPMENT OF A NEW TYPE OF BLACKCURRANT MARSHMALLOW WITH USING BASIL}

Присухина Наталья Викторовна - канд. техн. наук, доц. каф. технологий хлебопекарного, кондитерского и макаронного производств Красноярского государственного аграрного университета, г. Красноярск.

E-mail: nat3701@mail.ru

Ермош Лариса Георгиевна - д-р техн. наук, проф. каф. технологий хлебопекарного, кондитерского и макаронного производств Красноярского государственного аграрного университета, г. Красноярск.

E-mail: 2921220@mail.ru

Tuncuна Нэлля Николаевна - д-р техн. наук, проф. каф. технологий хлебопекарного, кондитерского и макаронного производств Красноярского государственного аграрного университета, г. Красноярск. E-mail: txkimp@mail.ru

Осетрова Полина Викторовна - магистрант каф. технологий хлебопекарного, кондитерского и макаронного производств Красноярского государственного аграрного университета, г. Красноярск. E-mail: polina.osetrova@yandex.ru

Цель исследования - разработка нового вида зефира на основе пюре черной смородины и базилика. Задачи исследования: оценить влияние замены яблочного пюре на черносмородиновое с добавлением базилика на студнеобразующую способность, органолептические и физико-химические показатели зефирной массы; разработать рещептуру зефира с использованием пюре черной смородины и базилика; оценить пищевую ценность нового вида зефира. Объектами исследования являлись образцы зесрира с использованием пюре черной смородины, пасты, настоя и порошка из базилика. За контрольный образец выбрана рецептура зесрира "Черносмородиновый», где составляет $74 \%$ пюре яблочное и 26 \% - черносморо-
Prisukhina Natalya Victorovna - Cand. Techn. Sci., Assoc. Prof., Chair of Technology of Baking, Confectionery and Macaroni Productions, Krasnoyarsk State Agrarian University, Krasnoyarsk.

E-mail: nat3701@mail.ru

Ermosh Larisa Georgievna - Dr. Techn. Sci., Prof., Chair of Technologies of Baking, Confectionery and Macaroni Productions, Krasnoyarsk State Agrarian University, Krasnoyarsk.

E-mail:2921220@mail.ru

Tipsina Nellya Nikolaevna - Dr. Techn. Sci., Prof., Chair of Technology of Baking, Confectionery and Macaroni Productions, Krasnoyarsk State Agrarian University, Krasnoyarsk.

E-mail: txkimp@mail.ru

Osetrova Polina Victorovna - Magistrate Student, Chair of Technology of Baking, Confectionery and Macaroni Productions, Krasnoyarsk State Agrarian University, Krasnoyarsk.

E-mail: polina.osetrova@yandex.ru

диновый припас. В экспериментальных рецептурах яблочное пюре было полностью заменено на пюре из черной смородины, добавлен базилик в виде настоя, пасты из свежей зелени и порошка. Порошок получен методом высушивания зеленой массы; паста - путем измельчения в однородную смесь; настой - путем заваривания горячей водой. Изготавливали зесрир по традиционной технологии. Приводятся результаты исследования по формированию качественных показателей зефира с полной заменой яблочного пюре на черносмородиновое и добавлением полуфабрикатов из базилика. Установлено, что при внесении полуфрабрикатов базилика наиболее высокими органолептическими свойствами обладали 
образцы с добавлением порошка. Определено оптимальное количество порошка базилика в рецептуре зефира. При замене $5 \%$ пюре черной смородины на порошок базилика формируются максимально высокие органолептические показатели, объем взбитой зефирной массы и стабильность пены. Повышается пищевая ценность изделия: наблюдается значительное повышение пищевых волокон, калия, кальция, фоссрора и витамина С. Полученные результаты позволяют рекомендовать разработанный новый вид зефира для расширения ассортимента «полезных» кондитерских изделий.

Ключевые слова: базилик, зефир, сахарные кондитерские изделия, качество.

The research objective was the development of a new type of marshmallow on the basis of blackcurrant puree and basil. The research problems were to estimate the influence of the replacement of apple puree with blackcurrant with addition of basil having gelling ability, organoleptic and physical and chemical indicators of marshmallow weight; to develop marshmallow recipe with using blackcurrant puree and basil; to estimate nutrition value of a new type of marshmallow. The objects of the research were marshmallow samples with blackcurrant puree, paste, infusion and basil powder. For the control sample the marshmallow recipe "Blackcurrant" with $74 \%$ apple puree was chosen and 26 $\%$ - with blackcurrant set. In experimental recipes apple puree was completely replaced with blackcurrant puree, the basil in the form of infusion, the paste from fresh greens and powder was added. The powder was received by the method of drying green material, the paste - by crushing in uniform mix; infusion - by adding hot water. Marshmallow was made according to traditional technology. The results of the research on the formation of quality indicators of marshmallow with full replacement of apple puree with blackcurrant and addition of semifinished products from basil were given. It was established that at introduction of semi-finished products of basil the highest organoleptic properties samples had those with powder addition. The optimum quantity basil powder in marshmallow recipe was defined. When replacing $5 \%$ of blackcurrant puree with basil powder the highest organoleptic rates, the volume of shaken-up marshmallow weight and stability of foam were formed. The nutrition value of the product rose: substantial increase of food fibers, potassium, calcium, phosphorus and vitamin C was observed. Received results allow recommending developed new type of marshmallow for the expansion of the range of "useful" confectionery.

Keywords: basil, marshmallow, sugar confectionery, quality.

Введение. В последние годы большое внимание уделяется использованию альтернативных, натуральных по происхождению источников сырья, способных обогащать продукты массового потребления необходимыми для организма человека нутриентами.

Кондитерские изделия, в том числе пастильные, обладают очень высокой энергетической ценностью (калорийностью), несбалансированным составом, десрицитом витаминов, минеральных веществ и пищевых волокон $[1,7]$.

Зефир пользуется спросом у населения. В его составе основными компонентами являются яичный белок и пектин, которые относятся не только к технологически необходимым, но и весьма полезным ингредиентам.

Традиционно в производстве зефира используется яблочное пюре. Однако в настоящее время у потребителей растет спрос на новые вкусы и ароматы кондитерских изделий.

Зефир является удобным объектом для обогащения растительными компонентами за счет невысоких температурных режимов при приготовлении зефирной массы $[1,3,6,7]$.

В данном исследовании в рецептуре зефира яблочное пюре заменено на пюре из черной смородины, а для придания вкуса и аромата вводится базилик.

Черная смородина богата пищевыми волокнами (4,8 г/100 г), большая часть которых представлена пектиновыми веществами, органическими кислотами (2,3 г/100 г), витамином C (200 мг/100 г), что в сочетании с сахаром дает хорошие студнеобразующие свойства, необходимые для производства пастильной группы изделий. Помимо этого пюре черной смородины богато калием (348 г/на 100 г), витамином A, холином.

Базилик обыкновенный является тропическим растением. В Сибири в основном культи- 
вируется. В 100 г базилика содержится около 3 г белка, из них 10 аминокислот, относящихся к незаменимым. Важно отметить, что в составе содержатся полиненасыщенные жирные кислоты и жирорастворимые витамины: А (264 мкг/100 г), бэта-каротин (3,142 мг/100 г). Также базилик содержит пищевые волокна (1,6 г/100 г), витамин K (414 мкг/100 г, при норме 120 мкг в сутки). По минеральному составу выделяются калий (295 мг/100 г), кальций (117 мг/100 г), магний (64 мг/100 г) и железо (3,17 мг/100 г) [5].

Одним из важных условий при производстве зефира - это создание устойчивой, стабильной пены. Для повышения стабильности пены и увеличения вязкости сбиваемой массы добавляют студнеобразователи. Пригодность различных видов пюре для сбивания пастильной массы оценивается в основном по его способности образовывать студни: чем выше эта способность у пюре, тем меньше его берется в рецептуру $[2,6]$.

Цель исследования: разработка нового вида зефира на основе пюре черной смородины и базилика.

\section{Задачи исследования:}

1. Оценить влияние замены яблочного пюре на черносмородиновое с добавлением базилика на студнеобразующую способность, органолептические и физико-химические показатели зефирной массы.

2. Разработать рецептуру зефира с использованием пюре черной смородины и базилика.

3. Оценить пищевую ценность нового вида зефира.

\section{Материалы и методы исследования}

Для производства зефира было использовано сырье: черная смородина - ГОСТ 6829-2015; caхар - ГОСТ 33222-2015; яичный белок - ГОСТ 30363-2013; патока - ГОСТ 33917-2016; агар ГОСТ 16280-2002; пюре яблочное - ГОСТ 32742-2014.

За контрольный образец взята рецептура зефира «Черносмородиновый», где $74 \%$ составляет пюре яблочное и 26 \% - черносмородиновый припас. В экспериментальных рецептурах яблочное пюре было полностью заменено на пюре из черной смородины, добавлен базилик в виде настоя, пасты из свежей зелени и порошка.
Подготовка базилика к применению. Свежую зелень базилика промывали, далее для получения пасты измельчали в однородную массу. Для получения настоя зелень заваривали горячей водой с температурой $85{ }^{\circ} \mathrm{C}$ в соотношении $50: 50$ и настаивали в течение 60 мин. Порошок получали методом высушивания в вакуумной сушилке при температуре $55^{\circ} \mathrm{C}$ с последующим измельчением. Ягоды черной смородины измельчали в блендере и подваривали с сахаром для повышения желирующей способности.

Технология производства. Для производства контрольного образца во взбивальную машину вносили сахар-песок, пюре яблочное, припас черносмородиновый и $1 / 2$ части белка, идущего по рецептуре. Смесь перемешивали во взбивальной машине в течение 9-10 мин. За это время кристаллы сахара полностью растворяются, рецептурная смесь за счет насыщения воздухом белеет и увеличивается в объеме. Затем вносили оставшийся белок и взбивали еще 9-10 мин. В сбитую массу постепенно вводили сироп с температурой $85-90{ }^{\circ} \mathrm{C}$ и взбивали еще 3-4 мин, далее добавляли вкусовые и ароматические вещества и красители. Готовую зефрирную массу отсаживали с помощью кондитерского мешка в виде полусфер и оставляли для структурообразования [4]. Технология приготовления экспериментальных образцов была аналогична, только яблочное пюре полностью заменяли на пюре из черной смородины. Порошок и пасту вносили на стадии сбивания зефирной массы в количестве $20 \%$ от массы. Настой добавляли при приготовлении сахаро-агаропаточного сиропа, заменяя им воду.

В исследовании применяли стандартные методы исследования анализа качества пастильной группы кондитерских изделий.

\section{Результаты исследования и их обсуждение}

На первом этапе исследования были проведены эксперименты по использованию различных видов полуфрабрикатов из базилика в рецептуре зефира.

В оценке качества кондитерских изделий, в том числе зефира, основными являются органолептические показатели. В таблице 1 представлены органолептические показатели зефира с различными наполнителями из базилика. 
Органолептические показатели зефира черносмородинового с базиликом

\begin{tabular}{|c|c|c|c|c|}
\hline \multirow{2}{*}{ Показатель } & \multicolumn{4}{|c|}{ Образец изделия } \\
\hline & $\begin{array}{l}\text { Контрольный } \\
\quad \text { № } 1\end{array}$ & $\begin{array}{l}\text { С настоем базилика } \\
\text { № } 2\end{array}$ & $\begin{array}{c}\text { С пастой } \\
\text { из базилика № } 3\end{array}$ & $\begin{array}{c}\text { С порошком } \\
\text { из базилика № } 4\end{array}$ \\
\hline Вкус & $\begin{array}{c}\text { Яблочный } \\
\text { с привкусом } \\
\text { черной } \\
\text { смородины } \\
\end{array}$ & $\begin{array}{l}\text { Черной смородины } \\
\text { со слегка уловимым } \\
\text { привкусом базилика }\end{array}$ & $\begin{array}{l}\text { Черной смородины } \\
\text { с привкусом } \\
\text { базилика }\end{array}$ & $\begin{array}{l}\text { Черной смородины } \\
\text { с привкусом базилика }\end{array}$ \\
\hline Запах & $\begin{array}{c}\text { Яблочно- } \\
\text { смородиновый }\end{array}$ & $\begin{array}{c}\text { Черной смородины со } \\
\text { слегка уловимым за- } \\
\text { пахом базилика } \\
\end{array}$ & $\begin{array}{l}\text { Черной смородины } \\
\text { с легким запахом } \\
\text { базилика } \\
\end{array}$ & $\begin{array}{l}\text { Черной смородины } \\
\text { с запахом базилика }\end{array}$ \\
\hline Цвет & Бледно-розовый & Грязновато-розовый & $\begin{array}{c}\text { Грязновато- } \\
\text { розовый }\end{array}$ & Ярко-розовый \\
\hline Консистенция & \multicolumn{2}{|c|}{$\begin{array}{c}\text { Мягкая, легко поддающаяся } \\
\text { разламыванию }\end{array}$} & $\begin{array}{c}\text { Мягкая, легко под- } \\
\text { дающаяся разламы- } \\
\text { ванию с признаками } \\
\text { расслоения } \\
\end{array}$ & $\begin{array}{l}\text { Мягкая, легко } \\
\text { поддающаяся } \\
\text { разламыванию }\end{array}$ \\
\hline Структура & \multicolumn{2}{|c|}{ Пенообразная, равномерная } & $\begin{array}{l}\text { Пенообразная, } \\
\text { неравномерная }\end{array}$ & $\begin{array}{c}\text { Пенообразная, } \\
\text { равномерная }\end{array}$ \\
\hline Форма & \multicolumn{2}{|c|}{$\begin{array}{c}\text { С хорошей формоудерживающей } \\
\text { способностью, без деформаций }\end{array}$} & $\begin{array}{c}\text { Слегка } \\
\text { расплывчатая }\end{array}$ & $\begin{array}{c}\text { C хорошей формоудер- } \\
\text { живающей способностью, } \\
\text { без десрормаций }\end{array}$ \\
\hline Поверхность & \multicolumn{2}{|c|}{$\begin{array}{c}\text { С выраженным рельефом, без грубого } \\
\text { затвердевания на боковых гранях } \\
\text { и выделения сиропа }\end{array}$} & $\begin{array}{c}\text { Рельеф слабо вы- } \\
\text { ражен, без грубого } \\
\text { затвердевания на } \\
\text { боковых гранях }\end{array}$ & $\begin{array}{c}\text { C выраженным рель- } \\
\text { ефом, без грубого за- } \\
\text { твердевания на боко- } \\
\text { вых гранях и выделе- } \\
\text { ния сиропа }\end{array}$ \\
\hline
\end{tabular}

Добавление пасты из базилика в сбивную массу приводит к ухудшению органолептических показателей. Появляется грязновато-зеленый оттенок изделия, который портит внешний вид готового продукта, наблюдается небольшое отделение жидкости, при отсадке изделий - расслоение консистенции.

Наилучшие результаты достигнуты при внесении порошка базилика во взбитую массу: появляется пряный запах и привкус, что в сочетании со вкусом смородины дает очень приятное ощущение.

На рисунке 1 представлена сравнительная характеристика органолептической оценки всех образцов зесрира.

Из таблицы 1 и графика на рисунке 1 видно, что при внесении настоя базилика в сахаро- агаро-паточный сироп изменений цвета и вкуса практически не происходит, наблюдается только слабовыраженный запах базилика. Наибольшее количество баллов набрали контрольный образец и образец с добавлением порошка из базилика.

На втором этапе исследовали влияние порошка базилика на физико-химические свойства изделий и желирующую способность ягоднобелковой массы во время взбивания.

Порошок вводили в рецептуру в дозировках 2; 5; 8 \% от количества пюре черносмородинового.

Дегустационная оценка зефира с добавлением порошка базилика представлена в виде диаграммы на рисунке 2. 


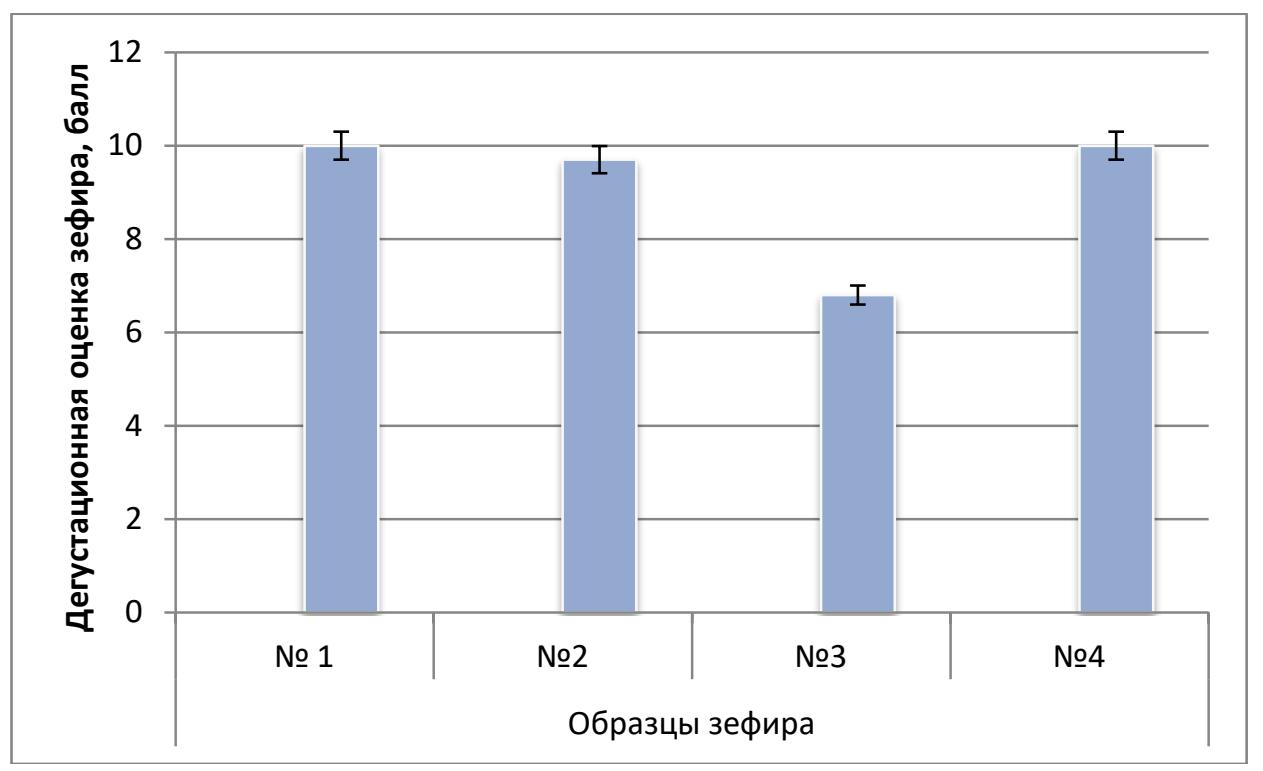

Puc. 1. Сравнительная органолептическая оценка зефира

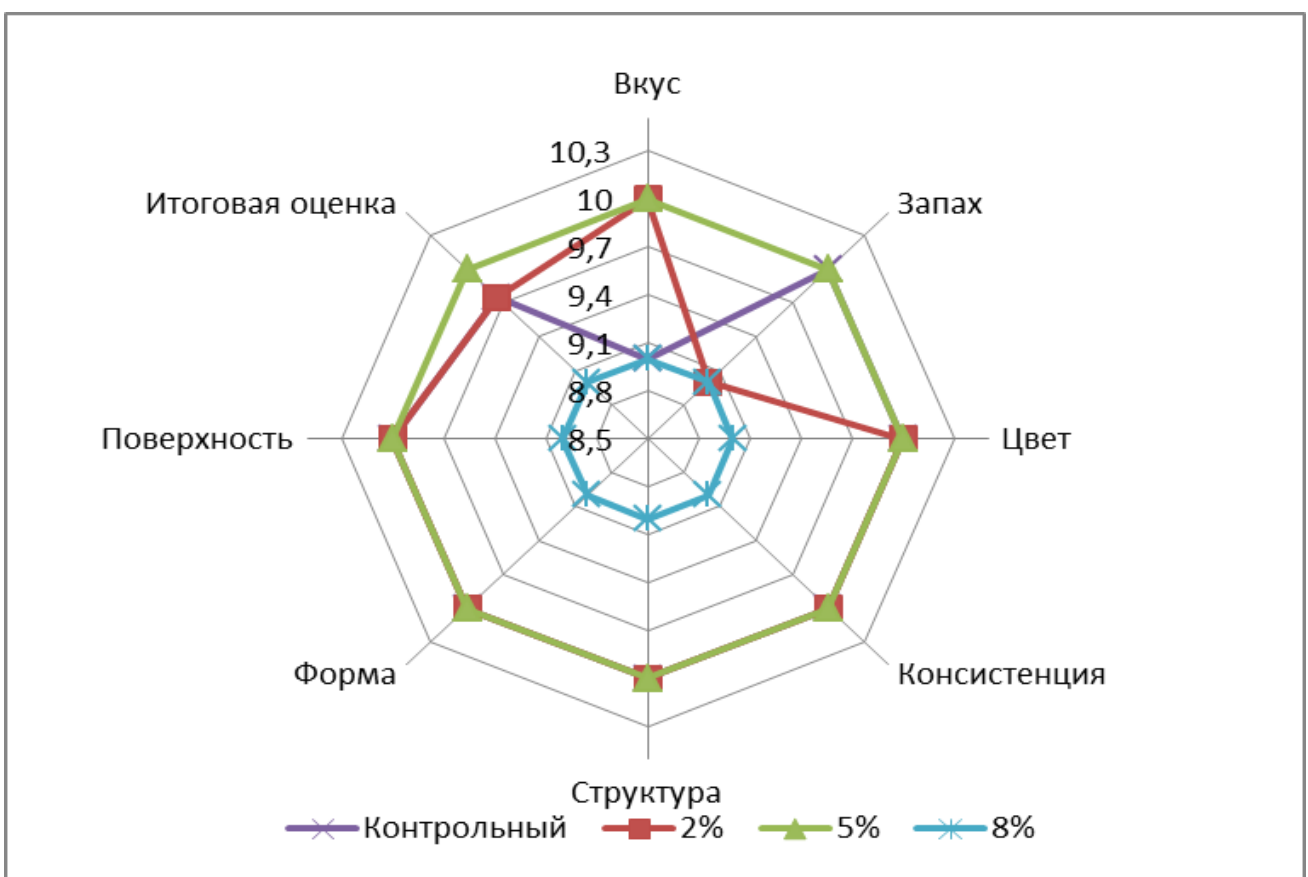

Puc. 2. Дегустационная оценка зефира черносмородинового

На основании исследования максимально высокими органолептическими показателями обладал образец с добавлением порошка базилика в количестве $5 \%$. Антоцианы, содержащиеся в смородине, дают яркий и стабильный цвет и вкус зефира без использования искусственных красителей и ароматизаторов (рис. 3).
При внесении порошка в количестве 8 \% наблюдается излишне выраженный вкус и запах базилика и появляются мелкие вкрапления порошка, что негативно сказывается на качестве продукта.

На рисунках 4, 5 представлены данные по пенообразующей способности и стабильности пены всех образцов. 


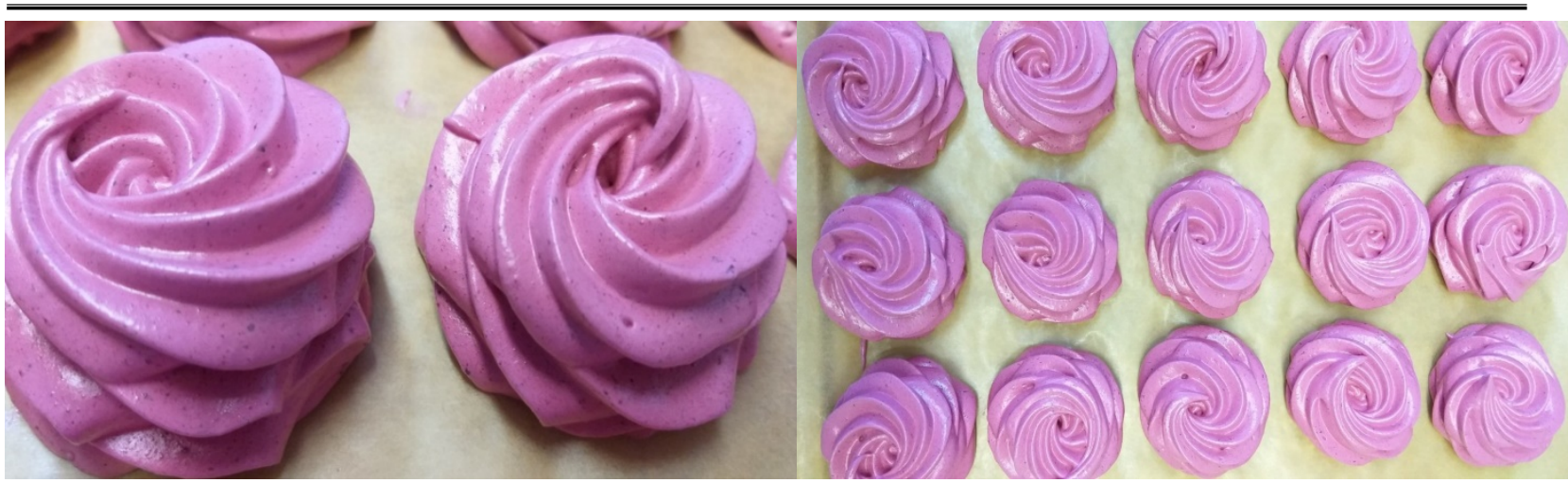

Pис. 3. Внешний вид зефира с порошком базилика в количестве $5 \%$

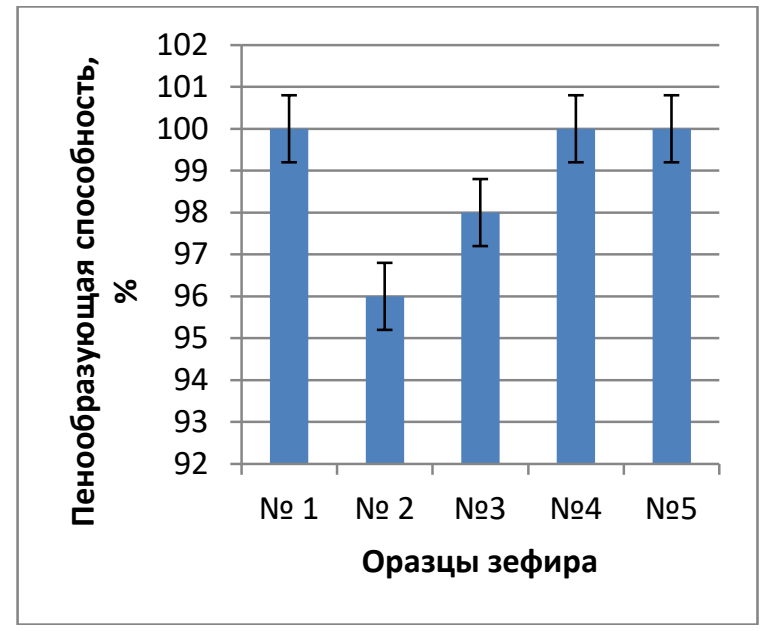

Puс. 4. Пенообразующая способность сбивной массы: № 1 - яблочно-смородиновылй зефир; № 2 - зефрир черносмородиновый; № 3 - зефрир черносмородиновый с $2 \%$ базилика; № 4 - зефиир черносмородиновый с 5 \% базилика; № 5- зефир черносмородиновый с 8 \% базилика

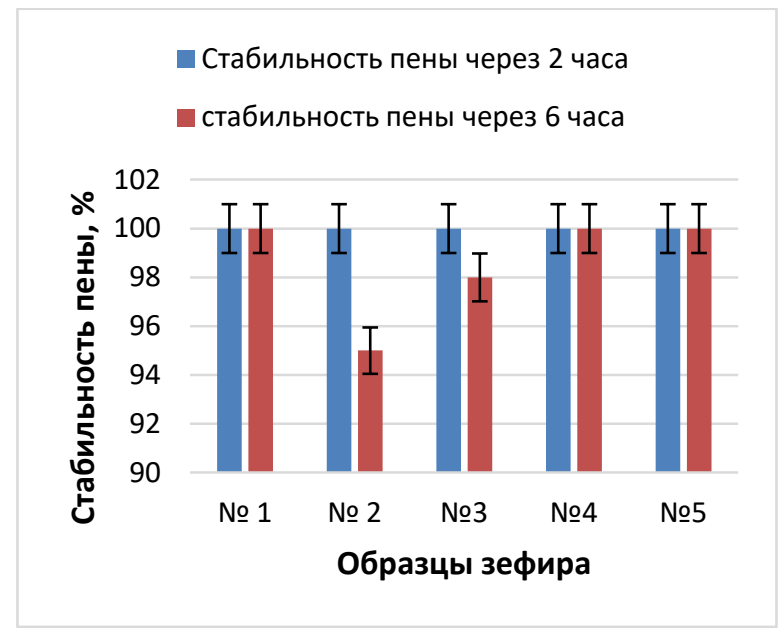

Puc. 5. Стабильность пены сбивной массы: № 1 - яблочно-смородиновый зефир; № 2 - зефир черносмородиновый; № 3- зефрир черносмородиновый с 2 \% базилика; № 4 - зефрир черносмородиновьй с 5 \% базилика; № 5 - зефир черносмородиновый с 8 \% базилика 
Исследования показали, что пенообразующая способность черносмородиновой сбивной массы ниже, чем в контрольном образце. Однако при внесении 5-8 \% порошка базилика стабильность пены через 2 и 6 ч составила $100 \%$, что свидетельствует о положительном влиянии порошка базилика на структурообразование взбивной массы.

В таблице 2 приведены результаты физикохимических показателей качества.

\section{Физико-химические показатели зефира}

Таблица 2

\begin{tabular}{|l|c|c|c|c|}
\hline \multirow{2}{*}{ Показатель } & \multicolumn{4}{|c|}{ Образец изделий } \\
\cline { 2 - 5 } & Контрольный & $\begin{array}{c}\text { С 2 \% порошком } \\
\text { базилика }\end{array}$ & $\begin{array}{c}\text { C 5 \% порошком } \\
\text { базилика }\end{array}$ & $\begin{array}{c}\text { C 8 \% порошком } \\
\text { базилика }\end{array}$ \\
\hline $\begin{array}{l}\text { Массовая доля влаги, } \\
\%\end{array}$ & 19,2 & 19,2 & 19,19 & 19,19 \\
\hline $\begin{array}{l}\text { Редуцирующие } \\
\text { сахара, \% }\end{array}$ & 8,01 & 8,01 & 8,012 & 8,01 \\
\hline
\end{tabular}

Изменения фризико-химических и органолептических показателей зефира черносмородинового согласуются между собой. Массовая доля влаги и содержание редуцирующих веществ в экспериментальных образцах отличался от контрольного всего на 0,01, что остается в диапа- зоне погрешности. На процесс студнеобразования порошок не оказал никакого влияния.

Определена пищевая ценность зефира контрольного образца и образца с полной заменой яблочного пюре на черносмородиновое и добавлением порошка из базилика в количестве 5 \% от массы пюре (табл. 3).

Таблица 3

\section{Пищевая ценность зефира исследуемых образцов}

\begin{tabular}{|c|c|c|}
\hline \multirow{2}{*}{ Пищевое вещество } & \multicolumn{2}{|c|}{ Содержание в 100 г продукта, г } \\
\hline & Контроль & С порошком базилика \\
\hline Белки, г & $0,84 \pm 0,02$ & $1,65 \pm 0,02$ \\
\hline Жиры, г & $0,21 \pm 0,03$ & $0,39 \pm 0,03$ \\
\hline Углеводы усвояемые, г & $77,65 \pm 0,09$ & $77,61 \pm 0,09$ \\
\hline Пищевые волокна, г & $0,45 \pm 0,02$ & $1,91 \pm 0,02$ \\
\hline Калий, мг & $49,14 \pm 0,08$ & $150,20 \pm 0,09$ \\
\hline Кальций, мг & $7,97 \pm 0,03$ & $88,31 \pm 0,04$ \\
\hline Фоссрор, мг & $8,23 \pm 0,03$ & $18,50 \pm 0,04$ \\
\hline Железо, мг & $0,23 \pm 0,02$ & $3,43 \pm 0,02$ \\
\hline $\mathrm{B}_{1}, \mathrm{Mr}$ & - & $0,01 \pm 0,01$ \\
\hline $\mathrm{B}_{2, \mathrm{Mr}}$ & $0,04 \pm 0,02$ & $0,07 \pm 0,02$ \\
\hline A, мкГ & $1,51 \pm 0,03$ & $3,40 \pm 0,03$ \\
\hline$\beta$-каротин, мг & $0,01 \pm 0,02$ & $0,02 \pm 0,02$ \\
\hline С, Мкг & $5,36 \pm 0,04$ & $7,4 \pm 0,04$ \\
\hline Энергетическая ценность, ккал/кДЖ & $316 / 1325$ & $320 / 1342$ \\
\hline
\end{tabular}

В новом виде зефира повышается пищевая ценность. Особенно наблюдается значительное повышение таких веществ, как пищевые волокна, калий, кальций, фоосфор и витамин С.
Выводы. Новый вид зефира, разработанный на основе черносмородинового пюре и порошка базилика, обладает высокими органолептическими показателями - ярким насыщенным цветом, кисло-сладким вкусом с ароматом и 
привкусом базилика, при этом отсутствуют искусственные красители и ароматизаторы.

За счет введения в рецептуру зефира порошка базилика увеличивается количество пищевых волокон на 1,5 г; количество калия, кальция и магния - почти в 3 раза, также в 2 раза увеличивается количество фосфора и железа. Наблюдается увеличение почти в 2 раза жирорастворимых витаминов: А и $\beta$-каротина.

Приятное вкусовое сочетание смородины и слегка пряный аромат базилика улучшают потребительские свойства, что позволяет расширить ассортимент «полезных» кондитерских изделий.

\section{Литература}

1. Барсукова И.Г. Разработка технологии пастильных кондитерских изделий повышенной пищевой ценности и срока годности в низком ценовом сегменте: автореф. дис. ... канд. техн. наук: 04.10.2017. Воронеж, 2017. $24 \mathrm{c}$.

2. Лобосова Л.А., Магомедов М.Г., Барсукова И.Г. и др. Технология выработки зефира с применением овощного пюре // Кондитерское и хлебопекарное производство. 2016. № 5-6 (165). C. 42-45.

3. Присухина Н.B., Типсина Н.Н., Туманова A.E. Влияние клюквенных полуфрабрикатов на качество и пищевую ценность мармелада и бисквита // Кондитерское производство. 2014. № 3. C. 10-11.

4. Скобельская 3.Г., Горячева Г.Н. Технология производства сахарных кондитерских изделий: учебник. М.: ПрофобрИздат, 2005. $416 \mathrm{c}$

5. Скурихин И.М. Химический состав российских пищевых продуктов: справочник / под ред. И.М. Скурихина, В.А. Тутельяна. М.: ДеЛи принт, 2002. 236 с.

6. Студенникова О.Ю., Бурыгина Е.В., Колпакова В.В. Пенообразующие раститель- ных белков // Кондитерское производство. 2010. № 6. C. 33-36.

7. Сушина А.Д., Сушин И.М. Технология зефира, обогащенного биологически активными веществами из фруктово-овощного сырья // Студенческий вестник. 2018. № 13-3 (33). С. 54-57.

\section{Literatura}

1. Barsukova I.G. Razrabotka tehnologii pastil'nyh konditerskih izdelij povyshennoj pishhevoj cennosti i sroka godnosti $v$ nizkom cenovom segmente: avtoref. dis. ... kand. tehn. nauk: 04.10.2017. Voronezh, 2017. 24 s.

2. Lobosova L.A., Magomedov M.G., Barsukova I.G. i dr. Tehnologija vyrabotki zefira s primeneniem ovoshhnogo pjure // Konditerskoe i hlebopekarnoe proizvodstvo. 2016. № 5-6 (165). S. 42-45.

3. Prisuhina N.V., Tipsina N.N., Tumanova A.E. Vlijanie kljukvennyh polufabrikatov na kachestvo i pishhevuju cennost' marmelada i biskvita // Konditerskoe proizvodstvo. 2014. № 3. S. 10-11.

4. Skobel'skaja Z.G., Gorjacheva G.N. Tehnologija proizvodstva saharnyh konditerskih izdelij: uchebnik. M.: ProfObrlzdat, 2005. $416 \mathrm{~s}$.

5. Skurihin I.M. Himicheskij sostav rossijskih pishhevyh produktov: spravochnik / pod red. I.M. Skurihina, V.A. Tutel'jana. M.: DeLi print, 2002. $236 \mathrm{~s}$.

6. Studennikova O.Ju., Burygina E.V., Kolpakova V.V. Penoobrazujushhie rastitel' nyh belkov // Konditerskoe proizvodstvo. 2010. № 6. S. 33-36.

7. Sushina A.D., Sushin I.M. Tehnologija zefira, obogashhennogo biologicheski aktivnymi veshhestvami iz fruktovo-ovoshhnogo syr'ja /I Studencheskij vestnik. 2018. № 13-3 (33). S. 54-57. 